\title{
Extinction induced social interaction in rats ${ }^{1,2}$
}

\author{
HANK DAVIS, UNIVERSITY OF MARYLAND \\ IRA DONENFELD, NAVAL MEDICAL RESEARCH INSTITUTE, BETHESDA, MARYLAND
}

Varying degrees of aggressive interaction appeared in all four pairs of $S$ s run in a two lever cage under different conditions of extinction. The nature of the aggression (ranging from postural threat to an animal's being chased from the cage) appeared to be related to the amount of extinction for each pair; i.e. where both animals were being extinguished there was a greater probability of a greater degree of aggression. Results were compared with those of a previous study involving reinforced performance in the same two lever cage.

In an earlier paper (Davis \& Wheeler, 1966) we investigated the social interaction of pairs of rats run on various combinations of schedules of reinforcement within the confines of a two lever-two feeder cage. Our conclusions supported the notion that operant control was useful in manipulating not only individual behavior, but also social behavior. That is, by pairing animals trained on different reinforcement contingencies, we were able to induce and study various types of social behavior, each related to the specific combination of schedules employed.

The present experiment was designed to investigate the initial emergence of schedule induced social behavior under conditions of extinction. Thus, although the training conditions here were basically similar to those of the previous study, during these experimental sessions reinforcement was withheld for one or both animals in each pair.

\section{Method}

Eight male Long-Evans rats served as Ss. All animals weighed between 175-200 gm and were four months old at the start of training. Ss were individually trained in a two lever-two feeder Skinner box for approximately five 100-reinforcement sessions per week over a two and a half month period. During training only one feeder and lever were operable, although the animal had access to the entire cage. Each experimental session was $30 \mathrm{~min}$. long and consisted of running an $\mathrm{A}$ rat and $a \mathrm{~B}$ rat together under the following conditions of extinction: 3

$\begin{array}{ll}\text { Pair } 1 & \text { DRL } 10 \text { ext } \\ \text { Pair 2 } & \text { DRL 10 ext } \\ \text { Pair 3 } & \text { DRL 10 ext } \\ \text { Pair 4 } & \text { DRL 10 }\end{array}$

Right Lever (B) FR 24 ext Naive FR 24 ext FR 24 ext

Cumulative response curves and DRL inter-response time (IRT) distributions were collected for each session, in addition to recording the number of responses each animal emitted on the opposite or untrained lever. All sessions were monitored on closed circuit TV. Results

Pair 1-During the first $10 \mathrm{~min}$. of the experimental session, each animal worked rapidly at his own lever.
During this period, B (on FR extinction) made a total of three responses on A's lever (DRL extinction). Early in the second $10 \mathrm{~min}$. of the session, $\mathrm{B}$ began responding quite frequently on $A^{\prime}$ 's lever. During this period $A$ crossed over into $B^{\prime}$ 's cage half although he did not respond on $B^{\prime}$ 's lever. In the 16 th $\mathrm{min}$. of the session after $B$ had made nine consecutive responses on A's lever, A ran to his own lever and pressed it rapidly several times. The animals then began to fight. Following 10 sec. of fighting, $B$ scampered out of the cage by squeezing under the hinged cage top. The session was then terminated.

Pair 2-In this pair only the A animal had previous schedule training (DRL 10). The B animal had no experimental history and was free fed for $24 \mathrm{hr}$. prior to the session. During the first $10 \mathrm{~min}$. A continuously responded on his own lever and went through a "time consuming" behavioral chain characteristic of DRL performance. This S's chain consisted of running to the back of the cage and gnawing on the wire mesh floor before returning to the lever. After $8 \mathrm{~min}$. had elapsed, the $B$ animal remained in the rear of the cage and gnawed with or groomed with $\mathrm{A}$ when he entered that area. After several such disruptions of A's chain, A began to make postural threats toward $B$ (described elsewhere, Keller \& Schoenfeld, 1952, p. 356). During these confrontations there was much squealing although there was no actual fighting. Throughout the second and third $10 \mathrm{~min}$. periods of the session, there was a marked decrease in A's IRTs, and an increase in the frequency of postural threats as $B$ continued to interact with and disrupt A's chain. There was no fighting during the session.

Pair 3-Like Pair 1, both animals of this pair were on extinction. During the first $10 \mathrm{~min}$. of the session, A worked regularly at his lever (DRL extinction), although following several "bursts" of responses he entered B's territory and began to groom B. During this $10 \mathrm{~min}$. period, B (on FR extinction) responded three times on $A^{\prime}$ 's lever. During the second $10 \mathrm{~min}$. period $B$ again pressed A's lever three times and $A$ continued to press his own lever and intermittently enter B's side and groom him. Occasionally after several response bursts, A would initiate a brief confrontation during which there was much squealing. During the third $10 \mathrm{~min}$. period of the session, the frequency of confrontations increased and A's IRTs decreased greatly. Four min. before the end of the session the animals began to fight consistently, continuing until the last minute of the session when $B$ scampered out of the cage with $A$ in pursuit.

Pair 4-In this pair of animals, only $B$ was on extinction (FR). A's DRL performance was characterized 
by a stereotyped sequence of gnawing on his foodcup while moving his body through a $180^{\circ}$ arc, beginning in his own side of the cage and moving gradually into B's territory. There was little change in this pair's behavior over the entire session. A's gnawing sequence resulted in stable DRL performance with a high frequency of reinforcement. $B$ continued to respond on his own lever and only rarely disrupted A's performance. These disruptions, however, invariably resulted in brief confrontations with $A^{\prime}$ 's almost immediate return to work. There was no fighting during the session. Discussion

The results of this experiment may be dealt with in the following three categories: (1) nature of social interaction (postural threat, fight, animal leaving the cage); (2) changes in IRT distribution; (3) number of responses emitted on the opposite lever.

(1) The following table may be helpful in discussing these results.

\begin{tabular}{|c|c|c|c|}
\hline air & Postural threat & $\begin{array}{c}\text { Fight } \\
\text { ves }\end{array}$ & $\begin{array}{c}\text { Animal leaving cage } \\
\text { yes }\end{array}$ \\
\hline Pair & yes & no & no \\
\hline Pair & yes & yes & yes \\
\hline air & yes & no & no \\
\hline
\end{tabular}

It is interesting to note that the two pairs in which $A$ and $B$ fought and B subsequently left the cage involved sessions in which both animals were on extinction. This would seem to indicate that the probability of this higher degree of aggression is positively related to the summed effects of the pair's extinction (and to the resultant summed frustration, if one cares to take this additional theoretical step). However, Thompson \& Bloom (1966), also using male hooded rats, report extinction induced aggression against naive satiated animals. This discrepancy may stem from the use of different criteria for "fighting." For instance, Thompson and Bloom report "vocalization and what appeared to be biting around the neck and back." (p. 335). Within the present paper such behavior (described as "squealing" and "grooming") was indeed recorded extensively although it has been classified separately from "fighting."

(2) The topic of socially induced changes in IRT distributions is dealt with extensively elsewhere (Wheeler \& Davis, 1966). It is worth noting, however, that aside from the trend toward longer IRTs characteristic of DRL extinction, there was a marked tendency toward very short IRTs in the presence of the second animal. As noted earlier in this paper, these response bursts often preceded aggressive behavior. Similarly, Thompson and Bloom state,"...there is a systematic relation between the increase in the rate of the previously reinforced response and the tendency for fighting to occur." (p. 336).
(3) In contrast to the results of the previous study (Davis \& Wheeler, 1966), there was no decrease in the number of B's responses on A's lever during the session. Thus, the decreasing number of such responses which emerged when performance of both animals was reinforced, and from which territoriality was inferred, was not the case in this study where one or both animals were on extinction. Accordingly, the notion of territoriality which was discussed in the previous study must be reconsidered here. It now appears that an earlier reinforcement on a lever will not in itself result in territorial behavior in the absence of continued reinforcement. Stating the case more loosely, it may be argued that once the territory "loses its value" (ceases to be reinforced), it is no longer worth defending against trespassers. Most of A's aggression under these conditions, therefore, occurred following bursts of unreinforced responding by A himself.

In closing it should be stressed that the procedure and conclusions are by no means meant to be exhaustive. This paper has attempted to describe the behavior resulting from initial exposure to extinction conditions in the presence of a second animal. Further analysis of social interaction and extinguished schedule performance are beyond the scope of this paper. It is the intent of these authors to emphasize the utility of operant methods in the experimental analysis of social behavior.

\section{References}

Davis, H., \& Wheeler, L. Social interaction between rats on different schedules of reinforcement. Psychon. Sci., 1966, 4, 389390 .

Keller, F. S., \& Schoenfeld, W. N. Principles of behavior. New York: Appleton-Century-Crofts, 1950.

Thompson, T., \& Bloom, W. Aggressive behavior and extinction induced response rate increase. Psychon. Sci., 1966, 5, 335-336. Wheeler, L., \& Davis, H. The social disruption of DRL performance. Mimeo.

\section{Notes}

1. From Bureau of Medicine and Surgery, Navy Department, Research Task MF022.01.03-1002. The opinions and statements contained herein are the private ones of the writers and are not to be construed as official or as reflecting the views of the Navy Department or the Naval Service at large.

2 . The authors wish to acknowledge the dedication and efficiency of Miss Jerilyn Hanson in the care and training of the experimental animals. Our thanks also to Dr. Ladd Wheeler for his critical comments on the manuscript.

3. On the FR (Fixed Ratio) schedule, reinforcement is contingent upon every $\mathrm{n}^{\text {th }}$ response. Thus, on an FR 24, each twenty fourth response is reinforced. On the DRL (Differential Reinforcement of Low Rates) schedule, reinforcement is contingent upon the passage of a specified minimum inter-response time. On the DRL $10 \mathrm{sec}$. for example, only a response which follows the previous response by at least 10 seconds is reinforced. Responses occurring sooner than the completion of the specified 10 sec. interval automatically recycle the timing mechanism and are not reinforced. Under conditions of extinction, all reinforcement is withheld. 